\title{
An empirical study to measure the impact of e-business on organizational performance with an emphasis on integrated production information
}

\author{
Hadi Meftahi $^{\mathrm{a}}$, Ali Nazeri ${ }^{\mathrm{b} *}$ and Mehdi Nosratpour ${ }^{\mathrm{c}}$
}

\begin{abstract}
${ }^{a}$ Department of industrial management, Payame Noor Universtiy, PO BOX 19395-3697, Tehran, Iran
${ }^{b}$ Department of Industrial Engineering, Damavand Branch, Islamic Azad University, Dmavand, Iran

${ }^{c}$ Department of Management, University Technology Malaysia, Kuala Lumpur, Malaysia

A B S T R A C T
\end{abstract}

\begin{tabular}{l}
\hline A R T I C L E I N F O \\
\hline Article history: \\
Received December 15, 2011 \\
Received in Revised form \\
February, 14, 2012 \\
Accepted 15 April 2012 \\
Available online \\
April 16 2012 \\
\hline Keywords: \\
Organizational performance \\
E-business \\
Supply chain management \\
Customer relationship \\
management
\end{tabular}

\begin{abstract}
During the past few decades, there have been different studies on e-business but there are limited numbers of works accomplished on measuring the impact of e-business on supply chain. Although e-business may not directly influence on organizational performance, it can have significant indirect impact on unifying customers and suppliers, which yields to a better performance of organizations. In this study, we perform an empirical study to measure the indirect impact of e-business on organizational performance. The proposed study of this paper designs a questionnaire and distributes it among 40 professional experts in various industries in province of Ilam, Iran. The survey examines four hypothesis for a possible correlation between e-business and integrated suppliers, e-business and customers, integrated customers and suppliers with organizational performance. The results of this survey confirm a positive relationship between all these components either directly or indirectly.
\end{abstract}

(c) 2012 Growing Science Ltd. All rights reserved.

\section{Introduction}

One of the most important issues for the success of any organization is to cope with advances in technology and implement new applications and techniques to increase their performance and reduce the cost of production. There are literally significant numbers of works associated to see how ebusiness could impact organizational performance. Ruiz-Mercader et al. (2006) performed an empirical evidence of the relationship between information technology and learning in small businesses as well as their influence on organizational performance. Their results indicated that individual learning along with individual and collaborative information technologies had a positive influence on organizational learning. Wu and Chen (2006) performed a hybrid performance measure system for e-business investments in high-tech manufacturing.

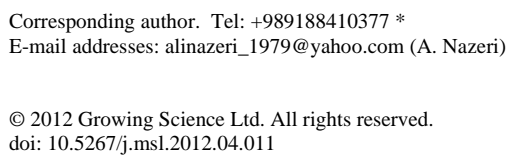


They implemented an integrative performance measurement with a three-level structure of organizational hierarchy, which includes corporate strategies, manufacturing decisions, and operational activities, along with a time-lag effect. The results indicated that time tag had positive influence on the performance measures of corporate strategies and they were substantially correlated with operational activities.

Sanders (2007) performed an empirical investigation of the impact of e-business technologies on organizational collaboration and performance. Sanders (2007) explained that organizational collaboration, the foundation of supply chain management could be enabled only by the development and implementation of e-business technologies. Organizational collaboration and information sharing could also contribute organizational performance. Sanders (2007) performed an empirical study to measure the relationship between organizational use of e-business technologies, organizational collaboration, and performance. The findings of the study suggested that implementation of ebusiness technologies influences performance both directly and indirectly and Intra-firm collaboration has direct influence on organizational performance, indirectly. The findings disclosed the complexity of organizational collaboration, underscore the relative importance for companies to promote internal collaboration.

Cegarra-Navarro et al. (2007) examined the relative significance of the four learning processes introduced by Huber including knowledge acquisition, knowledge distribution, knowledge interpretation and organizational memory on four various levels of e-business, which are null, external, relational and internal through an empirical investigation of 130 SMEs in the Spanish telecommunications industry. They reported that to use e-business, companies require to have the access of knowledge as prior steps. They also recommended that knowledge acquisition was necessary to progress from relational level to internal level. Kim et al. (2008) explored the impact of strategic positioning on firm performance in the e-business context.

Elbashir et al. (2008) developed a new technique, which is based on an understanding of the characteristics of business intelligence systems in a process-oriented structure. They employed the measure in an examination of the relationship between the business process and organizational performance, finding substantial changes in the strength of the relationship between industry sectors. The study reinforced the requirements to consider the specific context of use when designing performance measurement for IT-intensive systems. The study highlighted the need for further research examining contextual moderators to the realization of such performance benefits.

Phillips and Wright (2009) investigated the impact of e-business on organizational flexibility. The study was built based on previous works through two investigations. They first used the results of five case studies to develop a seven factors including alliance/joint decision management and intelligence, enterprise-wide change management, organizational learning, process oriented agility, network centric information management, leadership of transformation and knowledge exchange meetings. The paper also explained how the model could be used as a benchmarking technique and had the potential to become a key learning mechanism.

Wu et al. (2011) performed an empirical study on capability of e-business on organizational performance in Chinese firms. They argued that previous studies recommended that firms' overall ebusiness success could deliver better organizational performance but they did not determine how a firm leverages e-business investment to gain bigger e-business success. They believed only few works were associated with investigating the various influence of different levels of e-business success on organizational performance. Wu et al. (2011) tried to find the answers for two questions. The first question was to find out what capabilities impact a firms' capability to establish e-business success and reach greater organizational performance, where firm-level e-business success was measured by e-business service capability and IT-enabled collaborative advantage. The other question of their survey was on whether the two ways of measuring e-business success could result in 
various influences on organizational performance. They implemented a survey data from 152 Chinese manufacturing companies and their B2B e-business systems participants to test their theoretical hypotheses. They reported that both systems development and systems usage had substantial and positive influence on e-business service ability, which in turn led to bigger IT-enabled collaborative advantage. The findings were translated into the important role of a firm's application ability of ebusiness on e-business success. They also concluded that the application capability of e-business could act as one of the primary mechanisms through which the e-business investment could lead to bigger e-business success. The other findings of $\mathrm{Wu}$ et al. (2012) that IT-enabled collaborative advantage, compared with e-business service ability, had substantial influence on organizational performance. The study extended older e-business success studies by opening up the 'black box' between a firm's e-business investment and its e-business success.

Jiménez-Jiménez and Sanz-Valle (2011) studied innovation and organizational learning on organizational performance. Wang et al. (2012) studied some factors leading to the success of business-to-business (B2B) electronic marketplaces (EMs). They developed a model based on both organizational capability and market opportunity theories to find out the performance of B2B EMs. Their results recommended that the research model could explain the performance of B2B Ems and among the two service capabilities studied, service width contributed substantially to EM performance, while the effects of service depth were yet to be seen. In addition, the enabling organizational abilities and market opportunity items influenced EM performance both directly and indirectly through their enhancement of EM service provision capability.

The proposed study of this paper attempts to investigate the impact of e-business on organizational performance. The proposed study of this paper designs a questionnaire and distributes it among 40 professional experts in industry in a province of Ilam, Iran. The survey examines four hypothesis for a possible correlation between e-business and integrated suppliers, e-business and customers, integrated customers and suppliers with organizational performance. The organizations of this paper first presents details of the survey in section 2 and the results of our investigation are given in section 3. Concluding remarks are given at the end to summarize the contribution of the paper.

\section{The proposed model}

Integrated structure in information associated with production planning demonstrates information identity need to be shared within a supply chain and cooperation among different people could improve the quality of the information. Information sharing can be divided into the data based on demand and supply. The information associated with demand are demand prediction, customer classification and customer relationship management. Integrated information is based on providing appropriate strategy for ordering goods and different levels of inventory and production planning. Information sharing could always help all components of supply chain to provide appropriate plans a head of time.

\section{1 e-business}

An integrated supply chain can be measured based on different factors, which are sales prediction, master production plan, cooperation to provide appropriate needs, etc. Demand prediction helps better production design and material requirement planning. Information sharing across different corporations using recent advances of internet and its infrastructures could help improve supply chain management. Therefore, the following two hypotheses are proposed for our study,

H1: e-business influences integrated customers, positively.

H2: e-business influences integrated suppliers, positively. 


\subsection{Organizational performance}

There are different evidences to believe that a better level of integration in supply chain provides better advantages. It can increase sales, quality, delivery time and changeability. Therefore, it makes sense to consider the following two hypotheses for the proposed study of this paper,

H3: A higher degree of customer integration could improve organizational performance.

H4: A higher degree of supplier integration could improve organizational performance.

Fig. 1 shows details of the proposed study of this paper.

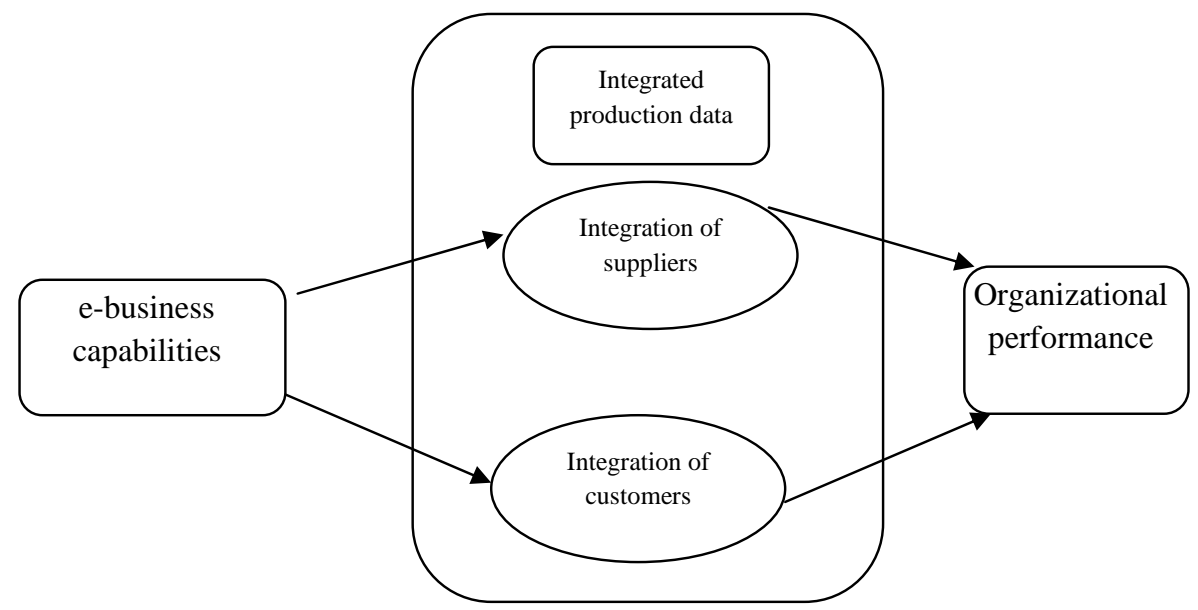

Fig. 1. The proposed model

\section{The results}

In this section, we present details of our survey performed among 40 industry experts who were involved in different industries in province of Ilam, Iran.

\section{1. e-business capabilities and integrated suppliers}

Table 1 demonstrates details of our Pearson correlation test between e-business capabilities and having a reliable integrated supplier.

\section{Table 1}

Pearson correlation test between e-business and integrated supplier

\begin{tabular}{llll}
\hline Variable & Standard deviation & Pearson correlation ratio & Degree of freedom \\
\hline e-business capabilities & 0.898 & 0.942 & 40 \\
Integrated suppliers & 0.977 & & 40 \\
\hline
\end{tabular}

As we can observe from the results of Table 1, there is a positive relationship between e-business capabilities and integrated suppliers with the significance level of 99\%.

\section{2. e-business capabilities and integrated suppliers}

Table 2 demonstrates details of our Pearson correlation test between e-business capabilities and having a reliable integrated customers. 
Table 2

Pearson correlation test between e-business and integrated customer

\begin{tabular}{llll}
\hline Variable & Standard deviation & Pearson correlation ratio & Degree of freedom \\
\hline e-business capabilities & 0.867 & 0.897 & 40 \\
Integrated customers & 0.932 & & 40 \\
\hline
\end{tabular}

As we can observe from the results of Table 2, there is a positive relationship between e-business capabilities and integrated customers with the significance level of 99\%.

\subsection{Integrated suppliers and organizational performance}

Table 3 demonstrates details of our Pearson correlation test between a reliable integrated supplier and organizational performance.

Table 3

Pearson correlation test between integrated supplier and organizational performance

\begin{tabular}{llll}
\hline Variable & Standard deviation & Pearson correlation ratio & Degree of freedom \\
\hline Integrated suppliers & 0.899 & 0.826 & 40 \\
Organizational performance & 0.954 & & 40 \\
\hline
\end{tabular}

As we can observe from the results of Table 3, there is a positive relationship between integrated suppliers and organizational performance with the significance level of $99 \%$.

\subsection{Integrated customers and organizational performance}

Table 4 demonstrates details of our Pearson correlation test between a reliable integrated customer and organizational performance.

\section{Table 4}

Pearson correlation test between integrated customer and organizational performance

\begin{tabular}{llll}
\hline Variable & Standard deviation & Pearson correlation ratio & Degree of freedom \\
\hline Integrated customer & 0.890 & 0.831 & 40 \\
Organizational performance & 0.971 & & 40 \\
\hline
\end{tabular}

As we can observe from the results of Table 4, there is a positive relationship between integrated customer and organizational performance with the significance level of $99 \%$.

In summary, all four hypotheses have been approved when the level of significance was set to 0.99, which indicates the relative importance of e-business on organizational performance.

\section{Conclusion}

In this paper, we have discussed the relative importance of e-business on improving the relative importance of business units. The recent advances on information technology have created the opportunities to reduce different cost components, which helps increase the productivity of organizations. The proposed model of this paper has investigated the effects of e-business on organizational performance via integration of supplier or customer in a province of Ilam, Iran. There were four hypotheses, which are correlation between e-business and integrated customer and supplier and between integrated customer and supplier with organizational performance. The results of four hypotheses were approved and the results showed a positive correlation between implementation of ebusiness and organizational performance. 


\section{References}

Cegarra-Navarro, J.G., Jiménez, D.J., \& Martínez-Conesa, E.A. (2007). Implementing e-business through organizational learning: An empirical investigation in SMEs. International Journal of Information Management, 27(3), 173-186.

Elbashir, M.Z., Collier, P.A., \& Davern, M.J. (2008). Measuring the effects of business intelligence systems: The relationship between business process and organizational performance. International Journal of Accounting Information Systems, 9(3), 135-153

Jiménez-Jiménez, D., \& Sanz-Valle, R. (2011). Innovation, organizational learning, and performance. Journal of Business Research, 64(4), 408-417.

Kim, Y.J., Song, J., \& Koo, C. (2008). Exploring the effect of strategic positioning on firm performance in the e-business context. International Journal of Information Management, 28(3), 203-214

Phillips, P.A., \& Wright, C. (2009). E-business's impact on organizational flexibility. Journal of Business Research, 62(11), 1071-1080.

Ruiz-Mercader, J., Meroño-Cerdan, A.L., Sabater-Sánchez, R. (2006). Information technology and learning: Their relationship and impact on organisational performance in small businesses. International Journal of Information Management, 26(1), 16-29

Sanders, N.R. (2007).An empirical study of the impact of e-business technologies on organizational collaboration and performance. Journal of Operations Management, 25(6), 1332-1347.

Wang, S., Mao, J.Y., \& Archer, N. (2012). On the performance of B2B e-markets: An analysis of organizational capabilities and market opportunities. Electronic Commerce Research and Applications, 11(1), 59-74.

Wu, I.L., \& Chen, J.L. (2006). A hybrid performance measure system for e-business investments in high-tech manufacturing: An empirical study. Information \& Management, 43(3), 364-377

Wu, J.N., Zhong, W.J., \& Mei, S.E. (2011). Application capability of e-business, e-business success, and organizational performance: Empirical evidence from China. Technological Forecasting and Social Change, 78(8), 1412-1425. 